\title{
The Application of Task-based Approach in English Grammar Teaching in Junior High Schools
}

\author{
Simin Wang \\ School of Foreign Languages, Shanxi Normal University, Linfen, 041000, China
}

\begin{abstract}
With the increasing of frequent international contact, people pay close attention to the cultivation of communicative competence in foreign language learning. Grammar course deserves a primary status on the curricula for English teaching reform. In order to improve students' grammar skills, the National New English Curriculum Syllabus advocates that Task-Based Language Approach should be adopted in English classroom, which has become popular since the mid-1980 in grammar teaching. When compared with traditional teaching method, TBLA could effectively settle the existing problems in grammar teaching. Therefore, this paper is to confirm that the application of Task-based Approach has a great impact on English language teaching and learning. Based on the theory of tasked-based approach, the paper summarizes the design principles of teaching tasks, teaching process and contexts. In the end, it encourages teachers to apply Task-based approach into English grammar teaching in junior high schools.
\end{abstract}

Index Terms - task-based approach, English grammar teaching, junior high school

\section{INTRODUCTION}

English is one of the most extensive languages in international exchange and cooperation. The task-based teaching theory has drawn abroad attention in language learning recently. As an important measure of evaluating teaching results, the productive and receptive abilities assign a position of special significance for English teaching. English grammar, as a basis of the speaking and writing ability, which plays a crucial role in communicating with other countries. Based on the second language acquisition theory, a foreign language leaner must possess grammatical competence. This will allow students to covey accurate information using syntax structure. It is also vital for instructors to lead an effective teaching method into grammar teaching in junior high school. Three teaching approaches have been commonly applied in junior high school for the past few years, which are called as prescriptive and descriptive approach, transformational-generative approach and functional approach. They would be introduced in detail in the following.

To begin with, in 1982, prescriptive and descriptive grammars are distinguished by some grammarians. The prescriptive grammarian specifies what is right or wrong while descriptive grammarian tries to avoid making judgments about correctness and concentrates on describing and explaining the way people want to say. Chomsky's Universal Grammar in 1996 develops the Transformational Generative grammar. Chomsky believes that grammar is an abstract set of rules for specifying sentence. It relates to investigating the internal structure of human mind rather than with communication. Teaching English as a Second or Foreign Language in 2001, Larsen-Freeman puts forward that functional grammar is a certain kind of logical language. Those who subscribe to functional grammar, rejecting the separation of form and meaning. The aim of these grammarians is to demonstrate that form, meaning and use work together. With the progress of the teaching reform, some aspects of functional grammar is difficult to see teaching flexibility. That entails three approaches have their own shortcomings. In this case, it is urgent and necessary to discover a more suitable and effective method for English grammar teaching.

Since the mid-1980s when the Task-based approach (TBA) was carried out in the classroom in India, it has been used widely due to its maturity, ubiquity, and feasibility. Task-Based approach is a method of instruction under Communicative Approach, which emphasizes tasks as the center of language teaching. The National New English Curriculum Syllabus (2001) which advocates the development of students' integrated abilities. For example, students can write and say a coherent and well-organized short article. Their ideas should be expressed in correctly English grammar. Besides students can successfully express ideas smoothly and write standard articles in correctly grammar. After that, the National New English Curriculum Syllabus (2001) advocates the application of TBA, especially teachers apply TBA into classroom teaching. Yet, there are still seldom students who can meet the grammar requirements. A great many students in junior high school complained that they have few opportunities to express and discuss their ideas. Thus, the purpose of this paper is to give a clear illustration about the TBA theories.

\section{THEORETICAL RESEARCHES ON TASK-BASED APPROACH}

\section{A. Definition of TBA}


Under the guidance of TBA, one of teachers' task is to stimulate students' creative thinking rather than just learning language forms. Yet, owing to the difference in academic background, purposes and methods, scholars have given out different definition about teaching task. Some representative figures would be listed in the following sections:

Long (1985) suggests that task is to do something for themselves with paying or without paying, such as drawing pictures, building houses and playing balls. Richards (1986) defines that task is an activity or action which learners carry out in language cognition, for instance, drawing a map as to key point. The task requires teachers to give specific criterions which are used to judge whether students achieve the goal successfully. Willis (1996) defines that the task is an experience in which learners communicate in the target language with the purpose of achieving an outcome. Brown suggests that "a task usually refers to a specialized form of technique or series of techniques closely allied with communicative curricula, and as such must minimally have communicative goals" (Brown, 2001, p.129).

1. Components of a Task

Just as making definitions for tasks, scholars have made efforts to identify the elements of a task. Among the scholars, Nunan (1989) hold the view that a task in TBA is made up of five components. The goal of TBA is to develop students' communicative ability, including discourse analysis, sociolinguistics applications and strategic competence. Input refers to the material which learners deal with issues. Resource models include newspaper, magazines, novels, films, songs, student works and so on. Students and teachers organize the collective activity in the classroom under the guidance of TBA. As usual, teachers are facilitators, organizers and monitors. Classroom instruction context was designed for tasks. Teachers also should consider whether tasks are carried out in or out of the classroom, partly or wholly.

2. Types of Tasks

Tasks were classified into six main types by Willis (1996). They are listing, ordering and scoring, comparing, problem-solving, sharing personal experiences and creative tasks. For example, in listing tasks, activities are mainly brainstorming and fact-finding. And results are a completed list or a drafted mind map. While in creative tasks, activities are combination of listing, ordering and sorting, out-of-class research, comparing and problem solving. The study results are appreciated by a wide range of audience who participate in classroom teaching.

3. Components of the TBA Framework

Jane Willis (1996) divide TBA into three sections, which are the pre-task, the task cycle, and the language focus. Pre-task: In this stage, teachers introduce the topic to students and try to stimulate students' interest. They should highlight the key words and phrases. Task cycle can be further divided into three steps: task, planning and report. In task step, students try their best to complete the tasks under the monitoring of the teacher. Next, students make preparation in pairs or groups for the report so that they can present the procedure and conclusion of their tasks in oral or written form. Then, students are invited to talk about the objections in their reports. By this means, students are offered the opportunity to take the initiative on their own learning. During this step, as an evaluator, teachers can judge students' performance.

\section{B. Principles of Designing Task}

"Task-based Approach offers the opportunity for "natural" learning inside the classroom. It emphasizes meaning over form but can also cater for learning form" (Ellis, 2003, p.16). As we all know, TBA offers an authentic situation for students in which they can acquire the target language naturally. When teachers design tasks or activities, they can consider the characteristics of the learning process. Kumaravadivelu (1993) suggests that when teachers are designing learning tasks, they must follow some psycho-linguistic principles. According to the characteristics of the learning process and the language teaching, there are four basic principles of designing tasks that teachers need to follow.

1. The Principle of Authenticity

The authenticity is the essence of the Task-based language teaching. It indicates that materials, situations and activities are derived from real life. Of course, the authenticity is just a relative concept. For receiving authentic language information, teachers may arrange materials as real as possible.

2. The Form-Function Principle

Task-based language teaching emphasizes not only the language forms but also meaning. Students are required to complete the tasks in a communicative way. In this way, students have a deeper understanding for the linguistics function. With advocating the combination of language form and functions, TBA avoids deficiencies of the traditional grammar teaching methods. In the light of the rule of language acquisition, students cultivate their communicative ability consciously or unconsciously simultaneously. Those tasks which ensure students to follow language forms quickly. Students can communicate successfully in the real situations if they have a good grasp of language structures.

3. The Task-Dependency and Task-Chain Principle

Tasks designed for students should reflect the law of language acquisition. They supposed to be chain and hierarchy. According to Nunan (2001), the task-dependency and task-chain principle refers to the fact that it should be in-depth gradually, for instance, from easy to difficult and from simple to complex gradually and the latter task should be based on the former one. Besides, teachers should pay more attention to students' learning process, which has been discussed in the beginning of this section. From students' cognitive ability, the design of the tasks should follow the task-dependency and task-chain principle. They can obtain corresponding knowledge and skills. It is beneficial for students to understand language knowledge.

4. The Principle of Learning by Doing 
Nunan (2001, p.25) proposes that “...learners must learn not only..., but also to develop the ability to use the language to get things done". What's more, the purpose of language teaching is to boost students' enthusiasm. During the learning process, students learn and practice grammar through continuous learning. In most cases, students are ready to communicate with partners for achieving their goals. Each of these principles is not isolated but connected. When teachers design tasks, they should follow each principle appropriately so that students' cognitive ability, language competence and communicative competence can be promoted and developed harmoniously.

\section{COMPARISON BETwEen THE Two Methods}

Grammar is an effective means to realize the purposes of informing, persuading, expressing or entertaining. It is a linguistic device which reflects the author's social values and cultural beliefs. The good spoken and writing abilities depend on language grammar, which are structured coherently in an appropriate style.

\section{A. Difference in Teaching Objectives}

The prescriptive grammar specifies what is right and wrong while descriptive grammar attaches great importance to avoiding making judgments about correctness and concentrates on describing and explaining the way people really want to say. The Transformational-Generative Approach regards language as a psychological phenomenon, seeking to describe language in terms of mental rules that enables us to generate grammatically correct sentences. The Functional Approach focuses on the social identities of language. It shows how the communicative purposes and functions of language are reflected in grammar. Yet, TBA stresses not only language forms but also meanings. The final goal of TBA is the cultivation of integrating language abilities, such as communicative abilities, creative abilities, and cooperative abilities. It inspires students to communicate with each other by using the right target language in their real social life. In consequence, it aims at developing students' affect attitude and learning strategy and makes efforts to increase their desire for English.

\section{B. Difference in Teaching Organization Forms}

Traditionally, the teacher is the main body of class activities. The Prescriptive and Descriptive Approaches is to describe language at the level of the sentence. It makes no attempt to analyze grammar as a tool for communication. We need to study it in communicative contexts. For example, students go on working memory and do some consolidated exercises. In this way, teachers neglect students' self-awareness and students receive information passively. Of course, this way cannot attain good teaching effect. Nevertheless, TBLA proposes that students are the main body in the classroom. The teaching procedure is divided into three steps: In the pre-task step, teachers give introduction to tasks and lead students into the topic of the classroom teaching. In the task-cycle step, students do their best to complete tasks in groups or pairs, and then they report and evaluate their products. At the language focus stage, through the analysis results, teachers make comments on students' outcomes and behaviors. They help them learn to summarize important language forms and provide some oral or written exercises. That is, an excellent teacher who suggest rather than indicate.

\section{Difference in Teaching Context}

The traditional teaching methods don't care whether the materials are close to students' real life. In other words, they are unable to put their theories or knowledge into practice. TBA demands that teachers should provide authentic and natural materials for students and they need to acquire the target language in real and natural situations. The content, topic, and pair work should be associated with the reality of students and meet their practical needs.

\section{Difference in Evaluation}

The traditional teaching methods take score as the main criterion, evaluating students' English level. Therefore, it has a low credibility and can't reflect the true level of students' English. To a certain extent, students will have a negative effect on English learning because of the fears of making mistakes. What's worse, it also makes students lose confidence or heart for English. The worst result is that they dare not to use English or take part in the class activities negatively.

In contrast, the evaluation method of TBA follows the learner-centered model. Teachers lay emphasis on the meaning expressed by students and let minor mistakes alone. They guide students to find out and correct the mistakes they made by themselves. In this way, students are encouraged to participate not only in the classroom activities actively but also enjoy the success of correcting mistakes on their own. Consequently, learners gain self-confidence and develop their interests for English.

\section{Application of tBA in English Grammar Teaching}

\section{A. Teachers and Students in TBA}

1. The Role of the Teacher in TBA

In the traditional teaching methods, "teachers"pedagogical role was to evaluate all learners' performance according to clearly defined criteria" (Littlewood, 2000, p.91). Different from the traditional grammar teaching methods, TBA shifts 
the center of teaching from teachers to students. Students master the target language through completing the pre-designed tasks under the help and guidance of teachers. Nunan (1989) suggests that teachers' main roles in TBA are task-designer, facilitators, and monitors and sometimes partners in their activities. According to Willis (1996), teachers have varied and dynamic roles in the TB language teaching process. The training of instructors' humanism spirit should be along with their moral construction, the pedagogical practice and campus construction.

In the pre-task stage, on the one hand, teachers are task-designers. The task should close to students' real life so that students can learn and use the target language naturally. Based on practical teaching, the assignment should accord with the condition of students and the culture goal of English project. That is, the task-dependency and task-chain principle, teachers should design different tasks or activities in different stages of the teaching process. Moreover, the difficulties of these tasks should be suitable to students' language competence. They achieve the aim of improving students' integrated language abilities, designing different types of tasks which correspond to students' English level. Furthermore, teachers who guide students into the topic of the class by creating related language situation. Teachers can make good use of modern multimedia provide vivid materials, such as diagram, words, sound, and video. By this means, students will be guided into the topic easily and quickly.

In the task cycle stage, teachers are organizers who arrange the tasks in an effective way and encourage students to participate in tasks actively. Then, teachers are monitors who remind students of complete the tasks as soon as possible. Despite of them, teachers also change their roles from one to another depending on the needs during this stage. The roles are:

Partner: As finishing all the tasks, teachers also take part in tasks as a partner of students.

Host: when students in groups or pairs to report their outcomes in turn or go on debating, teachers should perform as a host who create an active atmosphere and make sure the connection of each part is natural and smooth enough.

Observer: when students communicate with their classmates in target language, teachers should observe them carefully to find and correct these mistakes but avoid direct intervening too much.

Coordinator: in classroom settings, the teacher should always remind himself not to go over its time limit.

Instructor and helper: students run into problems which can't solve by themselves, teachers should give necessary help so that the activities can go on smoothly. In a word, during this stage, teachers change their roles from one to another frequently so that they can meet students' needs, helping students complete their tasks and achieve the goal of improving students' integrated language abilities.

In language focus stage, firstly, teachers are evaluator who give a summary and evaluate the products and students' behaviors after the report step of the task cycle stage. Secondly, teachers are language controllers who guide students to analyze and compare specific features of language form which have been used in tasks. In addition, teachers provide some oral or written exercises for students, consolidating new language knowledge. With analyzing the qualities of tasks and the performance of students, teachers are researchers who find their shortcomings and make progress in the coming teaching. With strategic planning, teachers start to focus on students and let students more active, student-oriented class has many advantages. Teachers' roles have a qualitative change, but their roles are still irreplaceable.

In the process of teaching organization, they have varied and dynamic roles. As allowing students to take part in class activities through designing effective tasks, teachers arise students' initiative and creative for English.

In the process of putting tasks into practice, teachers may build an academic environment that exploring the happiness of success and achieving the aim of learning and using language. That meets the needs of the students' study and development. As doing research constantly, they likely to improve teaching abilities and achieving more effective teaching results.

2. The Role of Students in TBA

Nunan (1989) puts forward that students are the center of TBA. They are participants and communicators who are to selected information in group activities. In terms of the New English Curriculum Syllabus which advocates TBA, students serve as many roles, such as participant, practitioner, discoverer, evaluator and reflector.

Each of those roles can be changed in teaching process and managed by learning assignment. Pre-task stage can often include playing a recording of student doing the task. Teacher introduces the topic and gives students clear instructions on content. The student finishes a task in pairs employing the language resources that they have as the teacher monitors and offers incentive. Students draw up a short oral or written article to represent the class what happen during the task cycle stage. That said, teachers' schedule has implications for students' progress. It is beneficial for the students to offer a proposal clearing up any language question. In other words, to figure out a new teaching method into the progress of modern education at this phase is the top priority. With supervising the teaching quality, we can get feedback for students. It is indispensable to spend a lot of time doing exercises. English practice is designed to improve the students' overall language capability. There is no doubt that TBA is a useful means for analyzing problems with others in target language. Such being the case, learners are enforced to summarize and write a reflection what they have gained from the task. As changing classroom management, students can easily seize the kernel points of a topic in the learning process.

\section{B. Teachers' and Students' Abilities in TBA}

The roles of teachers and students have a qualitative change in Task-based (TB) language teaching. Corresponding to 
it, the New National English Curriculum Syllabus advocates new requirements for their abilities.

1. Teachers' Abilities in TBA

TBA trains students' integrated language abilities just by having students complete all kinds of authentic tasks, so there are high demands for teachers' abilities. Unlike traditional approach, teachers need to reinforce comprehensive abilities. There are three main abilities: the interpersonal ability, the ability of designing tasks and the creative ability.

The interpersonal ability refers to that teachers can create an innovative idea how teach the same thing in different way. A trained teacher can provide the lively discussion on any lesson. Instructors should make students understand the meaning of each task and motivate students to do well towards this goal. Nevertheless, we have seen that in TBL, there is a close attention paid to the grammar of the language being studied at the last stage. Few teachers have a good interpersonal ability, so they can communicate with students smoothly and successfully and reach an agreement with students on the arrangement of the class. Therefore, teachers must possess a good interpersonal ability. Considering TBA as the building unit of the syllabus, teachers also need to have an ideal about the objective as a targeted outcome throughout the lesson. TBL isn't necessarily a framework without any structure, but the attention is on completing the task rather than teaching a specific language point. If you teach predetermined language or grammar, then of course, this might not come up in the task. Many teachers would use TBL alongside other teaching approaches, and maybe those are better suited to introducing set language structures that need to be included in the course. They would use this method complying with school setting in a structured program. Namely, teaching model is designed to develop their ability of finding questions. They preload vocabulary first, then go over the targeted area content and in subsequent lesson teachers use a task to reinforce both my targeted language but also to judge how well each person has understood the target. It allows students to wander through language acquisition as well as to sustain creativity for a long time. Tasks take the most important position in the TB language teaching. It means that the quality of the tasks decides the teaching effects, and the designing of tasks has a direct influence on the cultivation of students' language competence. Therefore, the course is organized to help students learn language in the efficient way possible.

The New English Curriculum Criterion indicates that the general aim of tasks is to facilitate the students' integrative ability of using English. The arrangement of the classroom should reflect the concept of student-centered. To strengthen students' practical ability, the project adopts real examples to motivate their energy. The successful application of tasks enables students to discover and solve problems. With the centered of students, the teaching method makes students analysis course properly. It will contribute to our language acquisition and gain good score. Teaching competence which promotes the development of the students' critical thinking.

2. Students' Abilities in TBA

Differ from receiving language knowledge passively, students become the main body of the classroom teaching, which requires students possess some abilities. Briefly speaking, these abilities include the communicative ability, the cooperative ability, the creative ability and the evaluative ability.

TBA is mainly to develop students' communicative ability in target language. It requires students to express and receive some information so that they can complete tasks by themselves. TBL may be counterproductive in contexts where students are used to lecture-mode step and other traditional language clarification approaches. New learning approach should be student-centered, engaging students actively in classroom practices. Compared with the formerly course, it attaches greater significance on verbal communication. Self-directed learning is an essential ability that learners could master their course content and assimilate the new messages. The new curriculum design is to foster learners' cooperative consciousness and innovation capacity. High-self assessment stimulates students to set accurate goals and let them aware of personal growth. The establishment of their autonomous learning ability is a vital subject for the teaching reform. TBA is ready to develop the personality traits, integrating their talents in sports and entertainment. Students thinking abilities can be improved under the new course criterion. Likewise, the role of the student in the new situation is a dynamic process, which respect them subjectivity. The multimedia can be taken to enhance students' operative skills.

It is common that tasks or activities are completed in groups or in pairs. Students need to get well along with their partners and decide what to do after discussing and planning. That said, each member of the group needs to finish their tasks actively. They should follow teachers' instruction and do what they are asked. Only in this way can they accomplish the tasks successfully and improve their integrated language abilities. Therefore, students need to possess the cooperative ability. The paper provides that the realization of teaching reform exists in the physical interaction between teachers and students. The cooperative and relevance theory can be implemented in teaching process. With having a good academic performance, students should take an active part in social activities. Teaching practice is to foster students' imaginative power, active learning and innovatory consciousness. At present, students are required to ask questions and capable of reasoning. It is valuable to train students to be skilled in raising problems.

To discover and solve questions, students must possess creative abilities so that they can achieve the aims of tasks. Ultimately, students should have the ability of evaluation, because students also perform as evaluator in the task cycle stage of the TB language teaching. When one group is asked to report their products, the others need to find out the excellent points and the shortcomings and give their comments.

\section{The Process of TBA in English Grammar Application}

The process of TBA in teaching junior high school English grammar is based on the related theory proposed by Jane 
Willis (1996) who presents that the framework of TBA teaching as following: "Pre-task (introduction to topic and task); Task cycle (task; planning; report); Language focus (analysis and practice)" (Willis, 1996, p.52). Willis' framework of TBA links meanings and forms together effectively and favors the communicative task more than the language form. Therefore, corresponding to pre-task, the task cycle and the language focus, the grammar lesson is designed into three stages: pre-grammar, while-grammar, and post-grammar. The following teaching procedures of TBA in English grammar are applied.

Pre-grammar (pre-task): Lead-in the grammar task

It is the beginning of grammar lesson to introduce what would be done in the class. In this stage, students and teachers should do the following things:

- Teachers try their best to help students understand the grammar points and goals of the grammar task, so that all students are clear about what they are going to study and in which style.

-Teachers stress the important and useful words and phrases. But they don't teach new vocabulary and grammar.

- Students do some warming-up exercises, for instance, listening to a record, so that they can recall relevant language knowledge learned before.

- Teachers leave students some time to think how deal with this grammar points.

While-grammar (the task cycle): Act grammar points and work out the outcomes. This is the most important stage which is made up of task, planning and report. The furthermore specific procedure is listed in the following:

In the task part, teachers and students should do the following things:

- Students try to complete the grammar points in pairs or groups and make best efforts to express themselves with target language.

- The teacher performs as a monitor and a supporter, walking around the classroom and helping students to express their ideas exactly.

- Teachers should lay emphasis on improving students' communicative abilities, cultivating students' confidence and stimulating students' interest for English in small groups.

In the planning part, the follow things should be done:

- Students make preparation for the report part in which students are asked to present the process and product of the task.

- Students plan and discuss what they want to say and know in groups.

- The teacher performs as an adviser, providing language knowledge when it is need.

- Students should lay emphasis on working out an accurate and appropriate writing under a well-organized way.

In the report part, teachers and students should do the following things:

- Some groups of students are asked to present their products while the others make comments and add different ideas.

- Teachers organize and evaluate the reports, but don't correct publicly.

Post-grammar (language focus): Review and consolidation

This stage can be divided into two steps, analyzing and practicing

In the analyzing step, teachers and students should do the following things:

- Students discuss and analyze the products which are presented in the report part of the while-grammar stage in pairs or groups. And they should not only stress the language forms but also the meanings of the outcomes.

- Teachers summarize the analysis made by students and make a final evaluation. At this time, teachers highlight the excellent points and correct some serious mistakes that students have made.

- Teachers provide a model, analyzing the features of the writing style and pointing out useful language forms. At the same time, students can take notes.

In the practice step, the following procedures should be finished.

- Teachers provide some consolidation exercises which tend be equivalent to our grammar tasks.

- Students do some exercises about useful language forms they have learned in the grammar tasks.

To summarize, these are our common procedures of grammar teaching under the guidance of the TBA. Teachers can also make some adjustments if it is necessary.

\section{CONCLUSION}

In this paper, the writer finds out the advantages of TBA and proves that it is a scientific teaching approach. Besides, the writer gives a clear illustration for teachers who are confused about TBA. Prescriptive and descriptive approach stresses language knowledge, but it neglects the cultivation of students' self-awareness and it is against the people-oriented, student-centered concept. Transformational-Generative approach lays emphasis on the participation of students in class activities, while it is time consuming and students don't have enough time to practice grammar of different types. Functional approach tends to train students' social skill and promotes students' potential for English. But it has strict rules, which lack of flexibility for language instruction.

TBA develops new teaching model for our class. It is still a convenient situation for managing students' activity in real scene. The form-function principle means that teachers will take into full consideration professional writing. That will signify striking a balance between language form and meaning. This principle will urge students to apply language 
form they learned in class into their real daily life. The task-dependency and task-chain principle claims that the tasks should be interrelated and get difficult gradually so that students find pleasure in enriching themselves. It will renew our method to foster well-balanced development and strive for progress on integrative competence. The principle of learning by doing has empowered students to bring out their best, enhancing them to think creatively and obtain good results. In the pre-task stage, the task holds the key to its teaching content. That entails students take part in the leading-in activities. Along with the increasing activities of teaching management, instructor's role has evolved from time to time. Meanwhile, the student's role under the combination of new assignment and teaching practice is a new subject. Teachers give a final evaluation and ask students to practice the language forms on the language focus stage. Students will advance the accumulation of knowledge and work together for a delicate atmosphere. As such, students reflect their behaviors in the classroom and find out the weakness so that they can accumulate experience for future. Overall, it is vital that there are various tasks for students to gain knowledge, broaden horizon and enrich their knowledge. The understanding of the teaching content also effects the legible and validity of teachers' teaching task design. Teachers treat several specific tasks as the kernel, guiding students to fulfil a task in the whole teaching process. In teaching the Advanced English, the task-based teaching allows learners to foster their language skills and make up for the lack of real condition in class.

The limitation of this paper is that it just illustrates the most confusing and important concepts about TBA. There still are other aspects which need to study in the future, for example, the ways to improve students' and teachers' abilities. The writer hopes others would do some researches in those aspects.

\section{REFERENCES}

[1] Brown, H. Douglas. (2001). Teaching by Principle: An interactive approach to language pedagogy. Beijing: Foreign Language Teaching and Research Press.

[2] Corony Edwards and Jane Willis. (2009). Teachers exploring tasks in English language teaching. Beijing: Higher Education Press.

[3] D Canale, M. \& M. Swain. (1980). Theoretical bases of communicative approaches to Second Language Teaching and Testing. Applied Linguistics, 1, 1-47.

[4] David Nunan. (2007). Practical English language teaching grammar. Beijing: Higher Education Press.

[5] Ellis, R. (2003). Task-based language learning and teaching. Oxford: Oxford University Press.

[6] Graves, D. H. (1978). Balance the basics: Let them write. New York: Ford Foundation.

[7] Kumaravadivelu, B. (1993). Maximizing learning potential in the communicative classroom. ELT Journal, 47, 12-21.

[8] Haozhi, Cao. (2011). A Brief Analysis on the Dynamic Role of English Teachers in Task-Based Language Teaching. Science Technology Information, 29, 640-641.

[9] Kay, H. \& T. Dudley-Evans. (1998). What teachers think. ELTJ Journal, 4, 308-314.

[10] Littlewood, W. (2000). Communicative language teaching. Beijing: Foreign Language Teaching and Research Press.

[11] Long, M.H. (1985). A Role for instruction in second language acquisition: Task-based language teaching. England: Multilingual Matters.

[12] Nunan, D. (1989). Designing tasks for the communicative classroom. Cambridge, UK: Cambridge University Press.

[13] Nunan, D. (1991). Language Teaching Methodology. London, UK: Prentice Hall International.

[14] Nunan, D. (1993). Design tasks for the communicative classroom. Cambridge: Cambridge University Press.

[15] Nunan, D. (2000). Communicative classroom tasks design. Beijing: People's Education Press.

[16] Nunan, D. (2001). Second Language Learning and Teaching. Beijing: Foreign Language Teaching and Research Press.

[17] Pincas, A. (1982). Teaching English Writing. London: Macmillan.

[18] Prabhu, N. S. (1987). Second Language Pedagogy. Oxford: Oxford University Press.

[19] Richards, J. \& Rodgers. T. (2001). Approaches and methods in language teaching. Cambridge: Cambridge University Press.

[20] Tribble, C. (1996). Writing. Oxford: Oxford University Press.

[21] Willis, J. A. (1996). A Framework for Task-based Learning. London: Longman.

Simin Wang was born in Changzhi, China in 1993. She is a post graduate student of Foreign Language in Shanxi Normal University. Her major field of study is Applied linguistics and Discourse analysis.

She currently works as a part-time translator and English teacher in language institutes, Linfen, China. Her research interests include second language acquisition, English language teaching and critical pedagogy. 